\title{
Fabrication, Characterization, and Impact of Heat Treatment on Sliding Wear Behaviour of Aluminium Metal Matrix Composites Reinforced with $\mathrm{B}_{4} \mathrm{C}$
}

\author{
Krishna Mohan Singh (i) and Akhilesh Kumar Chauhan \\ Department of Mechanical Engineering, K.N.I.T., Sultanpur, U.P. 228118, India \\ Correspondence should be addressed to Krishna Mohan Singh; kmssh1988@gmail.com
}

Received 5 February 2021; Revised 26 February 2021; Accepted 10 March 2021; Published 28 March 2021

Academic Editor: José António Fonseca de Oliveira Correia

Copyright (c) 2021 Krishna Mohan Singh and Akhilesh Kumar Chauhan. This is an open access article distributed under the Creative Commons Attribution License, which permits unrestricted use, distribution, and reproduction in any medium, provided the original work is properly cited.

\begin{abstract}
The aim of this research paper is to find the wear behaviour of Al7075 MMCs. In this investigation, the wear tests on the as-cast and age-hardened specimens were performed on an advanced rotary tribometer. The materials selected for the analysis are Al7075 as a matrix, and the reinforcements are boron carbide. By using stir casting, metal matrix composites are manufactured by adding $\mathrm{B}_{4} \mathrm{C}$ as a reinforcement particulate in Al7075. The fabricated composites were characterized and the wear behaviour of these composites was carried out on an advanced rotary tribometer. The wt. \% of the reinforcements was taken as $6 \%, 8 \%, 10 \%$, and $12 \%$. The almost homogeneous blending of reinforcements is shown by the microstructural characterization of Al7075 MMCs. It is observed that due to the rise in weight percentage of the reinforcement to $12 \%$ higher hardness is obtained. For $12 \%$ of reinforcements, there is an increase in hardness due to the heat treatment than that of the as-cast composites. From this study, it was found that the wear rate is the function of the applied load, microstructure, and volume fraction of the reinforcements. The wear rate was increasing with the sliding velocity.
\end{abstract}

\section{Introduction}

In recent years, a lot of research has been carried out for the aluminium matrix composite reinforced with ceramic particulates. In the literature study, it is seen that less work has been carried out regarding the effect of variation of the size of the reinforced particulates. A review on the tribological characterization of particulate reinforced with aluminium metal matrix composites has been published by Shinde et al. [1]. They reported that there is an increasing trend of using aluminium-based composites in sectors such as ground transportation, aerospace, and sports. They reported the reasons for using aluminium-based composites as high strength-to-weight ratio, wear resistance, corrosion, and fatigue. Dragut et al. [2] have produced Al/ $\mathrm{AlB}_{2}$ in situ composites via an exothermic chemical reaction between $\mathrm{KBF}_{4}$ and liquid $\mathrm{AA} 6060$ aluminium alloy at $850^{\circ} \mathrm{C}$. The presence of $\mathrm{AlB}_{2}$ compounds in the composite material was observed using an optical microscope and SEM. The main driving forces for the development of this material were the aerospace and automotive industries for both nonstructural and structural applications. Stoloff and Alman [3] published a research paper on innovative processing techniques for intermetallic matrix composites. They proposed processing techniques for composites through three routes, powder processing, melt processing, and vapour phase processing. The powder processing technique is consisting of various methods such as reactive consolidation, injection molding, mechanical alloying, $\mathrm{XD}$ processing, high energy rate forming, and microstructurally toughened composites. The melt processing technique includes pressure casting and directional solidification of eutectics. The vapour phase processing for composites includes the arc spray method, chemical vapour deposition, filament coating, and lowpressure plasma spray. 
Goni et al. [4] developed low-cost metal matrix composites (MMCs) for commercial applications by using locally reinforced aluminium composites and new castable aluminium MMCs. Al6061/WC/SiC hybrid composites have been synthesized using the stir casting technique under the various weight percentages of reinforcement [5]. Various properties such as wear resistance, hardness, tensile strength, and compressive strength were characterized and investigated in this research paper. From the microstructural analysis point of view, they reported that reinforcement particles were uniformly distributed without any clustering in the matrix. They further reported that precipitates of $\mathrm{Mg}_{2} \mathrm{Si}$ and undissolved $\mathrm{Al} 6(\mathrm{Fe}, \mathrm{Mn})$ are seen as a result of the interfacial reaction. They concluded that hardness of the composites has been enhanced. The enhancement in hardness of the composites is due to the incorporation of stronger and stiffer reinforcement in the matrix.

Manivannan et al. [6] fabricated nanocomposites Al6061/nano-SiC by using a liquid metallurgy technique. They presented the wear characteristics of the fabricated nanocomposites. They analyzed the worn surfaces as well as wear debris by using FESEM equipped with EDS. They claimed that the nanocomposite exhibits improved wear resistance as compared to the Al6061 alloy. They proposed that the worn surface shows different mechanisms such as abrasion, delamination, oxidation, and adhesive wear at different loads. The sliding wear test of $\mathrm{Al}-\mathrm{SiC}$ and $\mathrm{Al}-\mathrm{B}_{4} \mathrm{C}$ composites were performed on a pin-on-disc setup. Shorowordi et al. [7] analyzed the tribo-surface characteristics of the composites worn under different content pressures from $0.75 \mathrm{MPa}$ to $3 \mathrm{MPa}$ at a linear speed. The wear tests were performed against a commercial phenolic brake pad under dry conditions. The investigators recorded the coefficient of friction online. They characterized the worn surfaces using SEM equipped with EDS. They found that the wear rate of both the composites was increasing with the increasing contact pressure. They further reported that the surface roughness of Al-MMCs was increased with increasing contact pressure. For both the composites, the coefficient of friction slightly decreases with the increasing pressure. It was reported that a transfer layer of the phenolic counter body was seen on the pin of Al-MMC, and wear rate and coefficient of friction were higher for $\mathrm{Al}-\mathrm{SiC}$ as compared to those of $\mathrm{Al}_{-} \mathrm{B}_{4} \mathrm{C}$.

In an investigation, Rajesh et al. $[8,9]$ have analyzed the effect of reinforcing $\mathrm{Al}_{2} \mathrm{O}_{3}$ and $\mathrm{SiC}$ on the wear behaviour of hybrid aluminium MMCs on a pin-on-disc tribometer. They fabricated the composites by using the reinforcement $\mathrm{SiC}$ with $5 \%, 10 \%$, and $15 \%$ weight and $\mathrm{Al}_{2} \mathrm{O}_{3}$ with $5 \%$, $10 \%$, and $15 \%$ weight through stir casting. They reported that microstructural characterization indicates homogeneous mixing of the reinforcements. They concluded that the wear resistance of the composite was increased due to the addition of $\mathrm{SiC}$ and $\mathrm{Al}_{2} \mathrm{O}_{3}$. The wear tests were performed on both as-cast and age-hardened composites. They found that the rate of wear was reduced either by increasing the sliding speed or increment in the sliding distance. $\mathrm{Al}_{2} \mathrm{O}_{3}, \mathrm{~B}_{4} \mathrm{C}$, and $\mathrm{SiC}$ reinforced aluminium matrix composites were fabricated through stir casting and characterized for microstructure and interfacial reaction [10]. The investigators reported that the cast composites were subjected to hot extraction at $420^{\circ} \mathrm{C}$ with an extrusion ratio of 27 at a speed of $1 \mathrm{~m} / \mathrm{min}$ to reduce the porosity and enhance the particle distribution in the aluminium matrix. They reported that due to the addition of SiC particles, the grain became finer as seen in the microstructure. They observed macropores trapped in the center of the cluster of particles and micropores in the aluminium matrix. They further reported that the wettability of $\mathrm{B}_{4} \mathrm{C}$ was increasing in the air due to the formation of a layer of $\mathrm{B}_{2} \mathrm{O}_{3}$ on the $\mathrm{B}_{4} \mathrm{C}$ particles. Therefore, the distribution of $\mathrm{B}_{4} \mathrm{C}$ particles was better than that of $\mathrm{SiC}$ and $\mathrm{Al}_{2} \mathrm{O}_{3}$ in the composites processed in air. The EDS spectrum shows the presence of $\mathrm{O}, \mathrm{C}$, $\mathrm{Si}$, and $\mathrm{Al}$ in the interface reaction layer.

Leyland and Matthews [11] investigated the significance of hardness $(\mathrm{H})$ and elastic modulus (E) in controlling the wear. They proposed that there are evidences, which suggest that elastic modulus has an important effect on wear such as hardness. The investigators have suggested the concept of nanocomposite coatings having high $\mathrm{H}$ and low $\mathrm{E}$ for better toughness. So, the nanocomposite is considered better for optimizing the resistance against wear in industrial materials. They also discussed the importance of elastic strain and fracture toughness to find the wear behaviour. In an investigation, Sharma et al. [12] examined the wear behaviour of hybrid aluminium alloy composites reinforced with $\mathrm{SiC}$ and $\mathrm{RE}$ (Rare Earth) mixture $\mathrm{CeO}_{2}$ and $\mathrm{La}_{2} \mathrm{O}_{3}$ through stir casting. They reported that, about $2 \%$ of rare Earth content can enhance the ultimate tensile strength and microhardness of percentage elongation of Al6063. They observed an improvement of about $42 \%$ in wear rate composites as compared to base alloys.

The volume fraction or weight fraction of the reinforcement particles are also affecting the microstructure, mechanical properties, and wear resistance of the composites. Different investigators have taken different weight fractions of the reinforcement. Rajesh et al. [9] have taken $5 \%, 10 \%$, and $15 \%$ of the reinforcement. Fenghong et al. [5] considered wt. fractions of the reinforcement as $10 \%, 15 \%$, and $20 \%$. In another investigation, $2 \%, 4 \%, 6 \%$, and $8 \%$ wt. of reinforcement were taken for the fabrication of the Al6061 alloy composites [13].

The aim of this investigation is to synthesize and characterize the Al7075- $\mathrm{B}_{4} \mathrm{C}$ composites followed by a sliding wear test. This investigation aims to synthesize MMCs with Al-7075 as matrix and boron carbide $\left(\mathrm{B}_{4} \mathrm{C}\right)$ as reinforcement with varying sizes through stir casting. The results were interpreted on the basis of optical microstructure, mechanical properties, and surface morphologies.

\section{Materials and Procedures}

2.1. Materials. In the present investigation, $\mathrm{Al} 7075$ has been selected as a matrix and $\mathrm{B}_{4} \mathrm{C}$ of average size $50 \mu \mathrm{m}$ with 99.9\% purity has been selected as reinforcement. The major constituents of Al7075 in wt.\% are $\mathrm{Zn} \mathrm{5.8 \% ,} \mathrm{Mg} \mathrm{2.4 \% ,} \mathrm{Cu}$ $1.5 \%, \mathrm{Fe} 0.2 \%, \mathrm{Cr} 0.2 \%$, and balance $\mathrm{Al}$. The chemical analysis of the reinforcement is given in Table 1. 
TABLE 1: Chemical analysis of boron carbide particles.

\begin{tabular}{lcccccc}
\hline Element & Boron & Carbide & Si & Ni & O & \\
\hline Wt. $\%$ & 77.2 & 22.3 & $<0.1$ & $<0.01$ & $<0.1$ & $<0.08$ \\
\hline
\end{tabular}

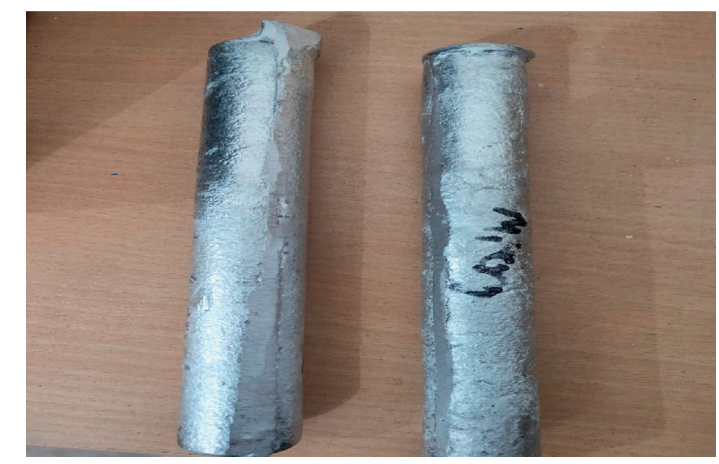

Figure 1: Casting ingot.

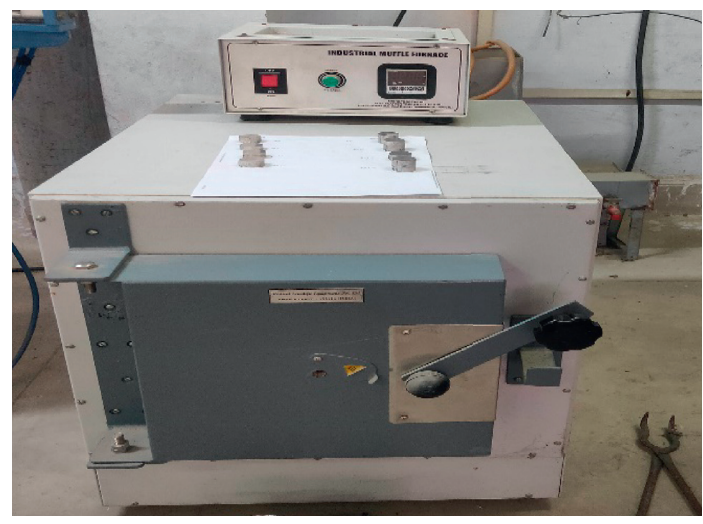

Figure 2: Industrial muffle furnace setup.

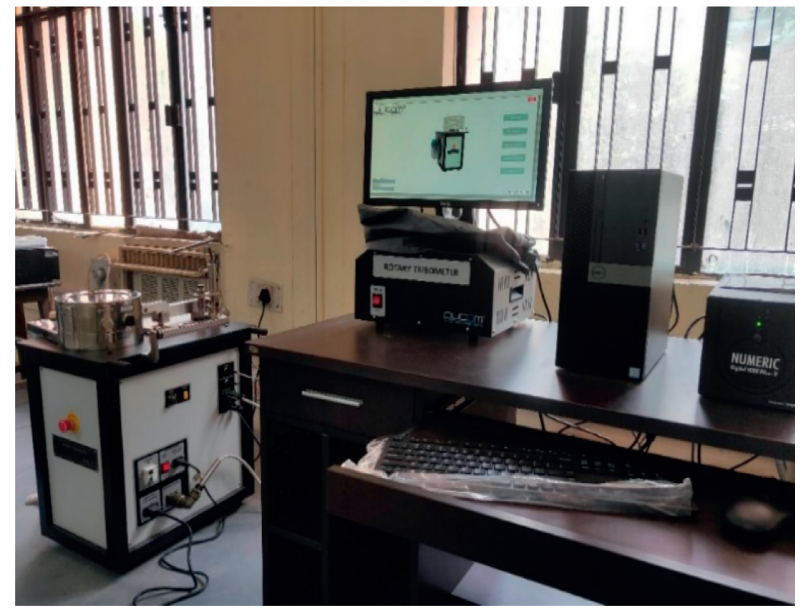

(a)

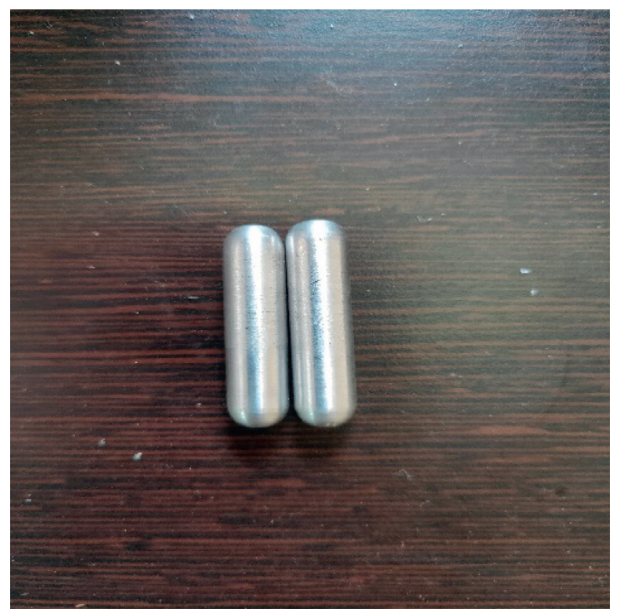

(b)

FIGURE 3: (a) Pin-on-disc advanced rotary tribometer and (b) specimens for the wear test. 


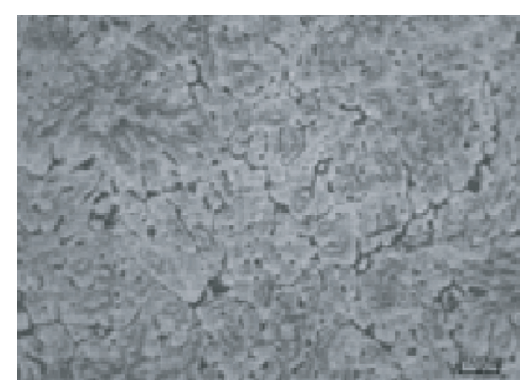

(a)

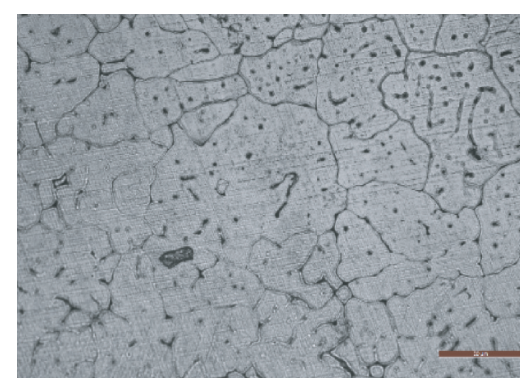

(d)

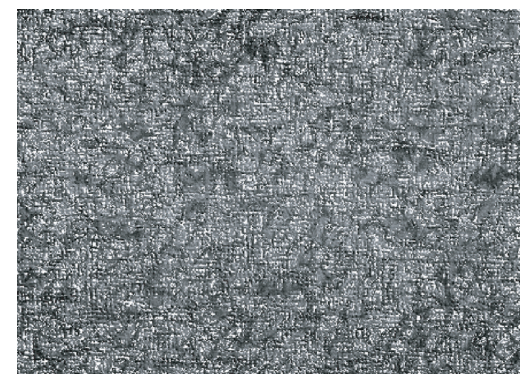

(g)

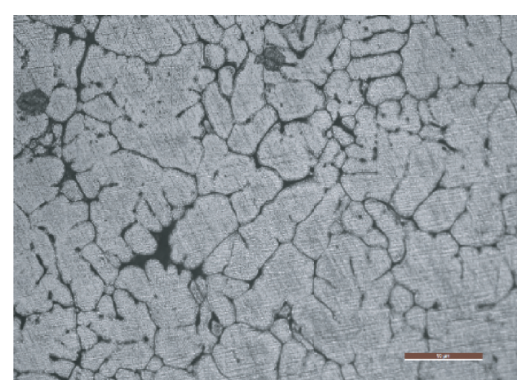

(b)

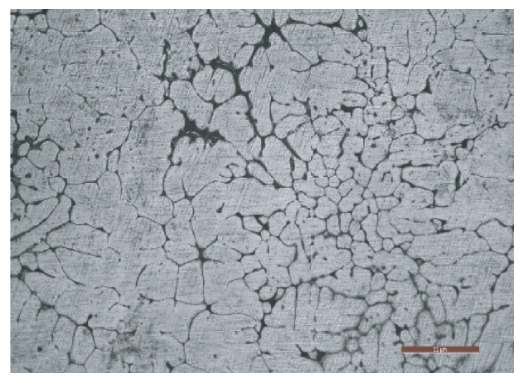

(e)

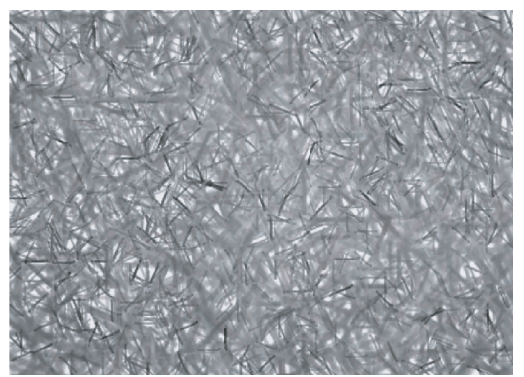

(h)

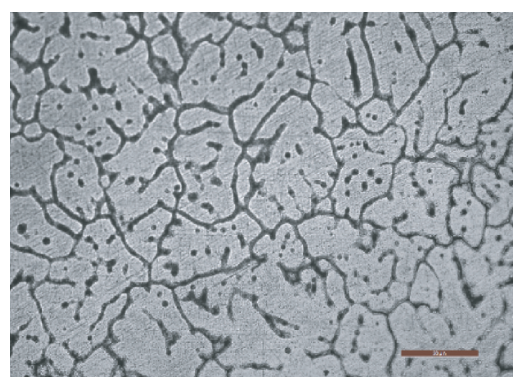

(c)

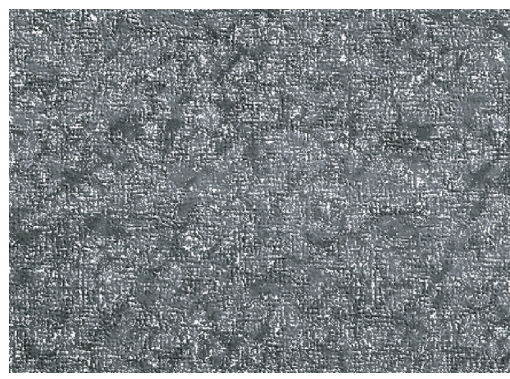

(f)

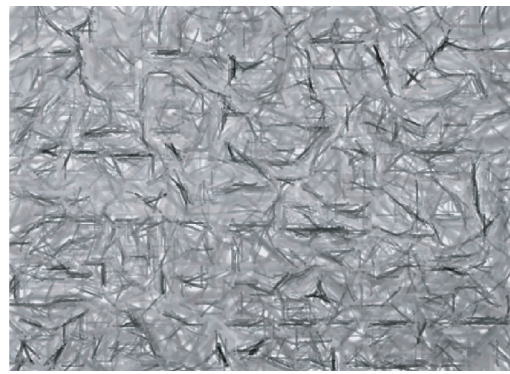

(i)

Figure 4: Microstructure examinations of pure Al7075, as-cast, and age-hardened specimens. (a) Al7075 alloy. (b) Al7075/B ${ }_{4} \mathrm{C}-6$ wt. $\%$ as-

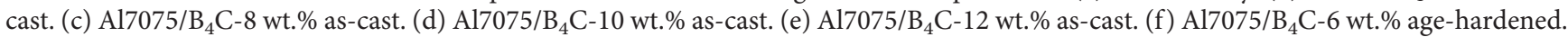

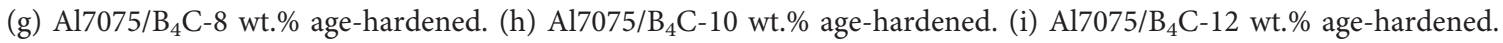

2.2. Procedures. Al7075- $\mathrm{B}_{4} \mathrm{C}$ composites are developed using stir casting at varying weight fractions of $\mathrm{B}_{4} \mathrm{C}(6 \%, 8 \%$, $10 \%$, and $12 \%$ ) using vacuum furnace. The weight fraction of the reinforcement was decided on the basis of various investigations $[5,8,13]$. Liquid aluminium alloy was superheated to a temperature of $750^{\circ} \mathrm{C}$ during the liquefying process. $\mathrm{B}_{4} \mathrm{C}$ was added to the required measurements of the molten metal and mixed with a stirrer at speed of $600 \mathrm{rpm}$ as per the norms followed by Rajesh et al. [9]. The liquid $\mathrm{Al} 7075-\mathrm{B}_{4} \mathrm{C}$ was poured into a die and allowed to cool. The composites were then withdrawn from the die and the composites are shown in Figure 1.

2.3. Heat Treatment. In the muffle furnace (Figure 2), the ascast samples were heat-treated up to $465^{\circ} \mathrm{C}$ for two hours. After $2 \mathrm{hrs}$ of the solution treatment, the specimens were quenched in the water. These were subject to age hardening at $120^{\circ} \mathrm{C}$ for five hours followed by air cooling.

2.4. Hardness Test. The hardness of the composites was determined by using the Brinell hardness tester. The indenter used was of $2.5 \mathrm{~mm}$ diameter, and the major load was $187.5 \mathrm{kgf}$.

2.5. Wear Test. A sliding wear test was performed on the advanced rotary tribometer manufactured by Ducom, Bangalore, to assess the wear behaviour of the composites, as shown in Figure 3(a). A circular disc made of austenitic stainless steel (SS-304) was the wear disc used in the tribometer. The disc thickness and diameter were $60 \mathrm{~mm}$ and $10 \mathrm{~mm}$, respectively. The wear diameter has been fixed at $40 \mathrm{~mm}$. The hardness of the disc was $65 \mathrm{HRC}$. The specimens for the wear test were made (Figure 3(b)). The wear tests were conducted as per the standard of ASTM G99-05.

\section{Results and Discussion}

3.1. Microstructural and EDS Analysis. The microstructure of the fabricated composites in as-cast and age-hardened conditions is shown in Figure 4. From the microstructure of the ascast composites, the same micropores are seen in Figures 4(b)4(e) as compared to pure aluminium alloy (Figure 4(a)), 


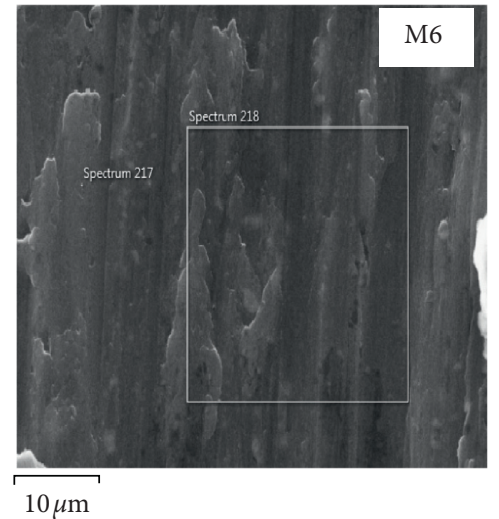

(a)

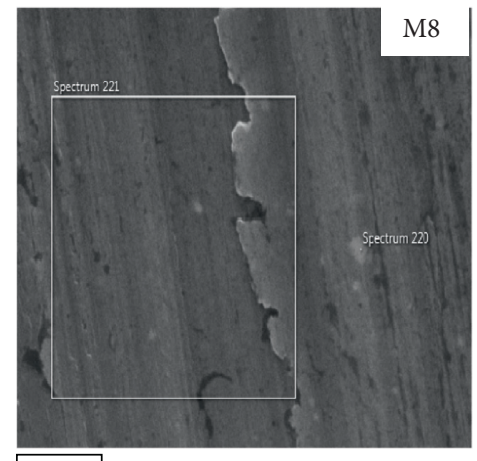

(b)

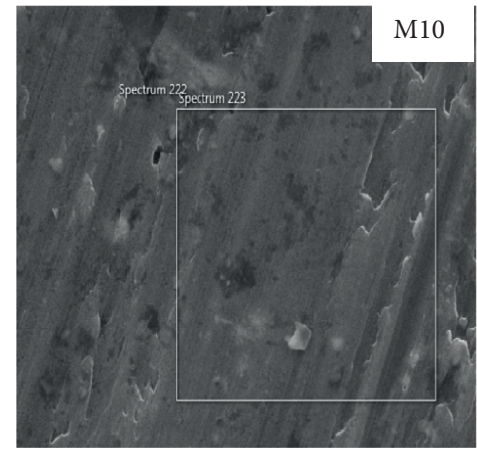

(c)

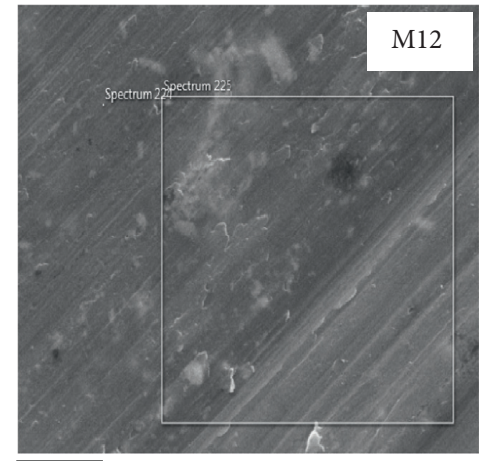

(d)

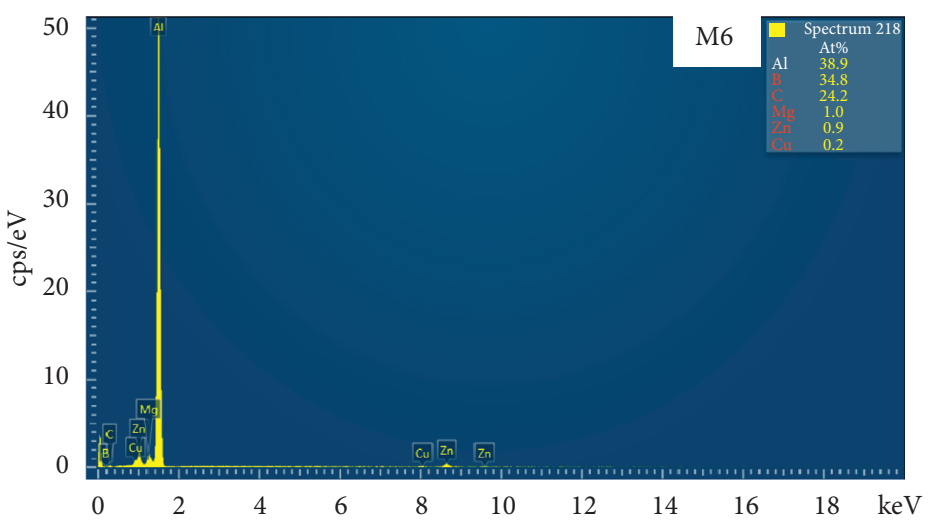

(e)

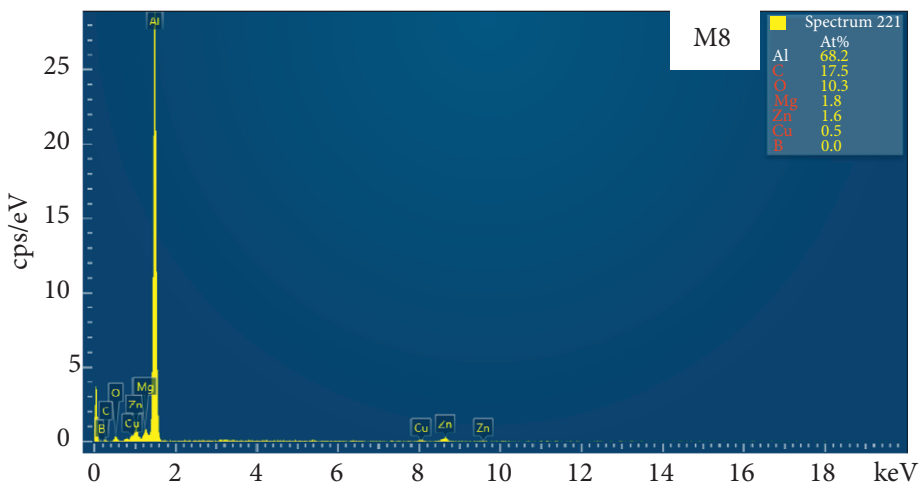

(f)

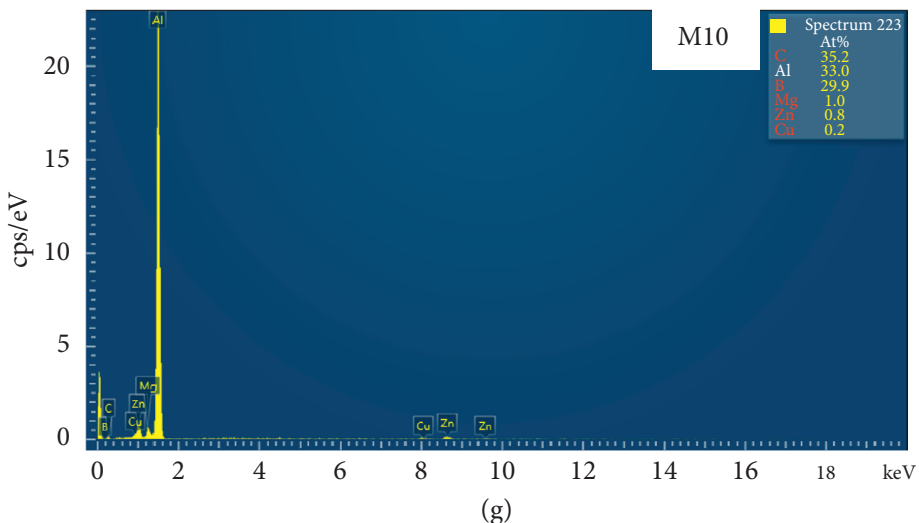

(g)

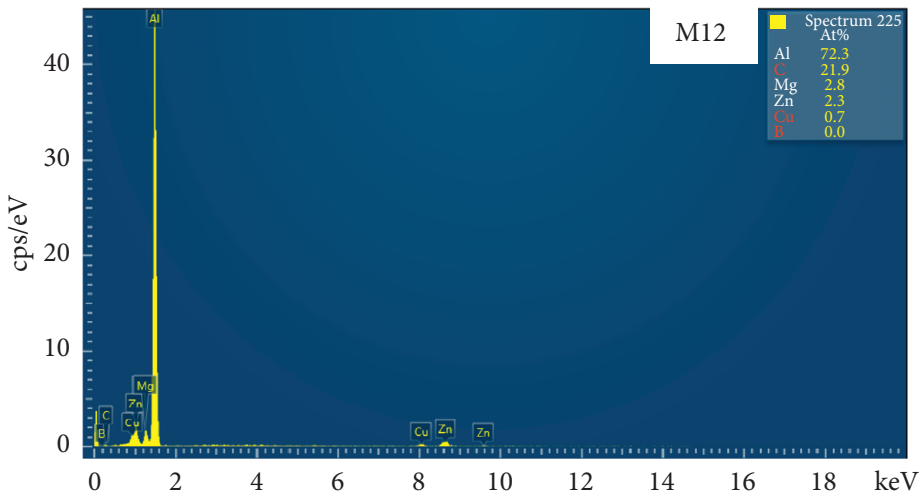

(h)

FiguRE 5: SEM micrographs and EDS spectrums of different compositions of the Al7075-B ${ }_{4}$ C composites. (a) M6. (b) M8. (c) M10. (d) M12. (e) M6. (f) M8. (g) M10. (h) M12. 


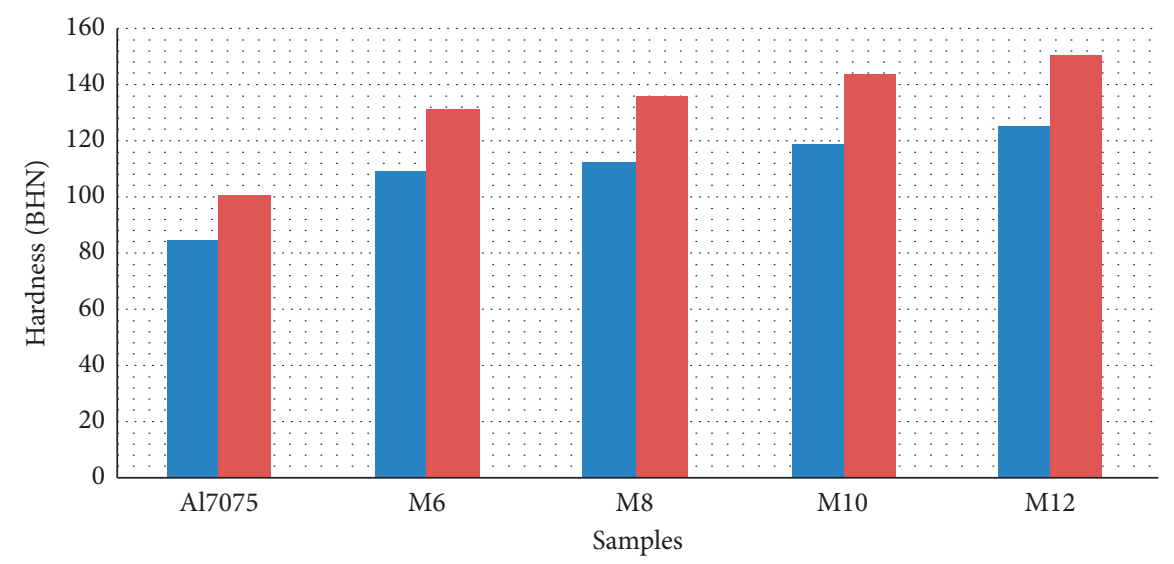

- As-cast

- Age-hardened

Figure 6: Hardness number for samples of different conditions.

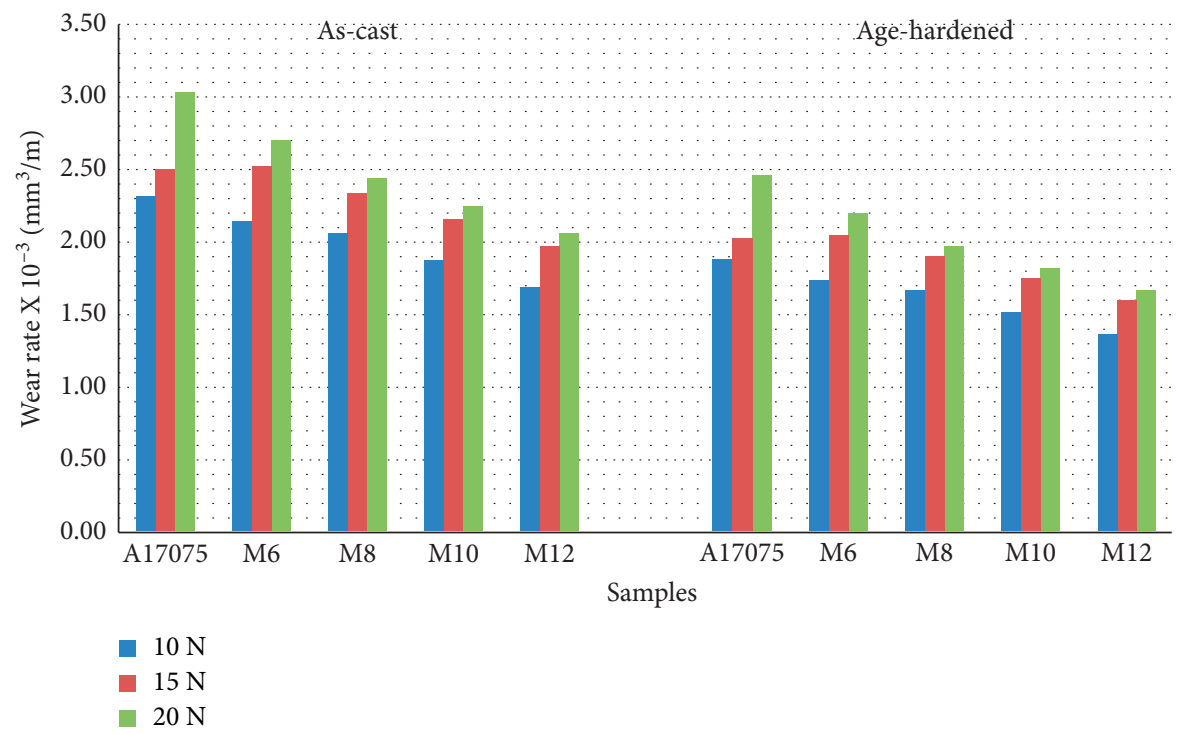

Figure 7: The wear rate of as-cast and age-hardened specimens at $1.5 \mathrm{~m} / \mathrm{s}$.

Al7075-10\% $\mathrm{B}_{4} \mathrm{C}$ composite, and all age-hardened composites. This observation is in agreement with those reported by Rajesh et al. [9]. It is also seen that $\mathrm{Al} 7075-10 \% \mathrm{~B}_{4} \mathrm{C}$ composite shows uniform distribution of the $\mathrm{B}_{4} \mathrm{C}$ particles as compared to others in which clusters of particles are seen. Due to age hardening, there is a refining of the grains as well as reduction of pores.

To identify the elemental composition of the compounds of the composites, EDS of the composites in cast condition was performed (Figure 5). The EDS analysis indicates the composition of mainly Al7075 alloy along with some boron carbides. This observation is similar to those reported by Rajesh et al. [9] (Figure 4).

3.2. Hardness. Ten positions were used for each component on the as-cast and age-hardened specimens. The average of all the results was considered and shown in Figure 6. In
Figure 6, it can be observed that due to the addition of $\mathrm{B}_{4} \mathrm{C}$ particles to the Al7075, there is an increment of hardness. However, further increment in hardness is very less with increasing the wt.\% of the reinforcement. These results are in agreement with those reported by Rajesh et al. [9] in which hardness was increasing with $10 \%$ reinforcement and then decreasing. From Figure 6, it is observed that there is an increase in hardness due to age hardening in the composites. These results are similar to those reported by Rajesh et al. [9].

3.3. Effect of Age Hardening and As-Cast Conditions on the Wear Rate. The wear tests of the composites both as-cast and age-hardened were performed for a sliding speed of $1.5 \mathrm{~m} / \mathrm{s}, 2.5 \mathrm{~m} / \mathrm{s}$, and $3.5 \mathrm{~m} / \mathrm{s}$ and with varying load. The results are shown in Figures $7-9$. From the results, it is observed that the wear resistance of the composites is 


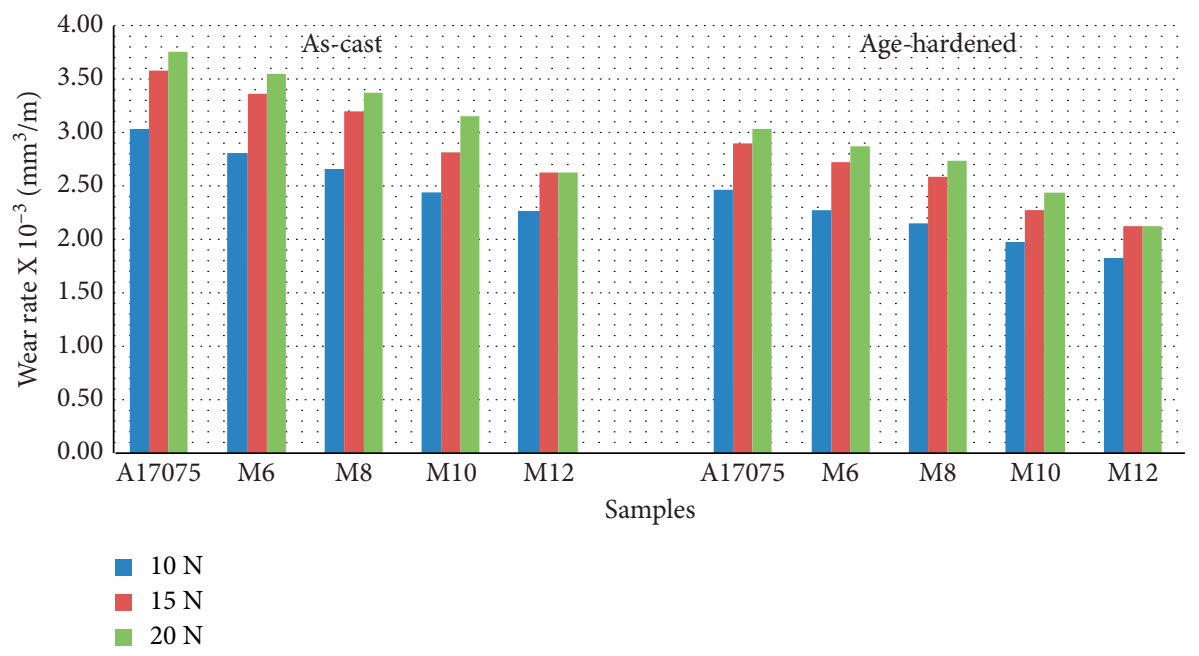

Figure 8: The wear rate of as-cast and age-hardened specimens at $2.5 \mathrm{~m} / \mathrm{s}$.

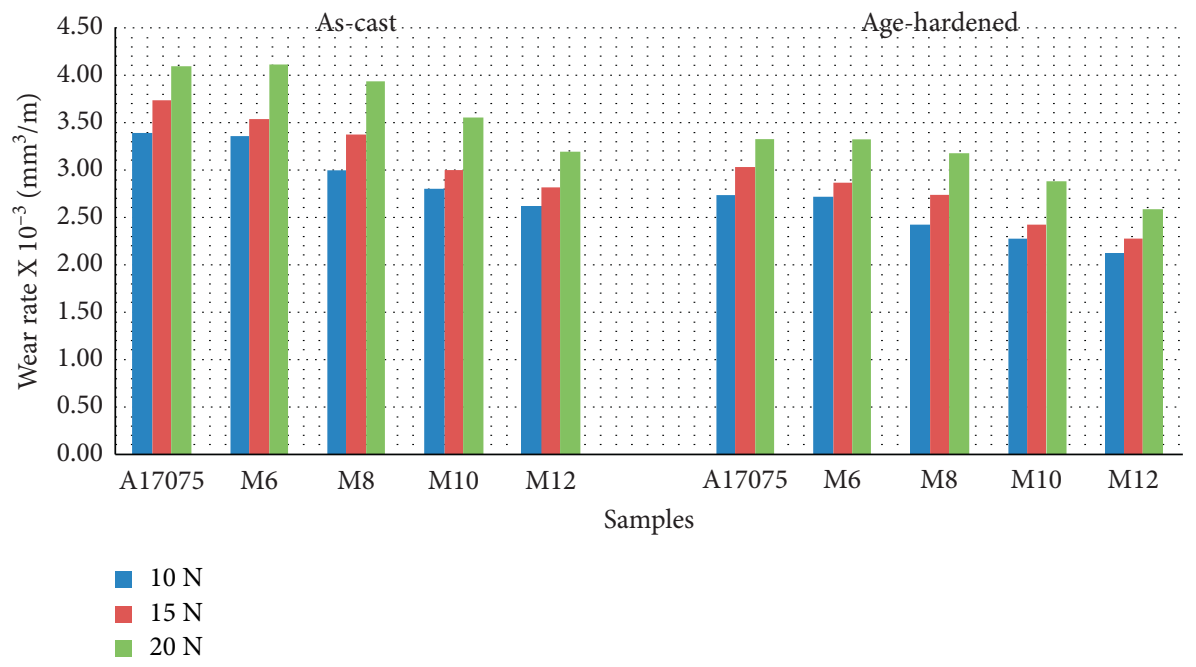

Figure 9: The wear rate of as-cast and age-hardened specimens at $3.5 \mathrm{~m} / \mathrm{s}$.

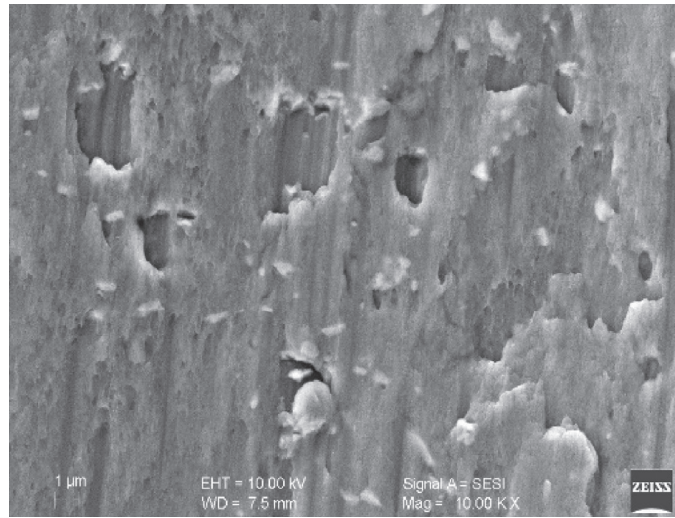

(a)

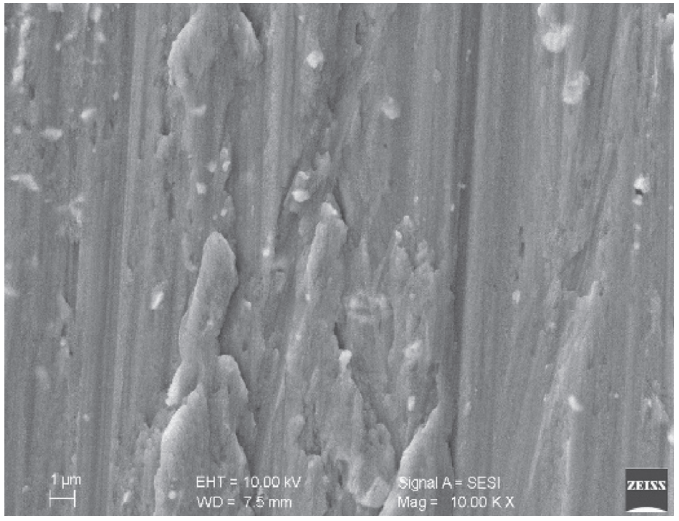

(b)

FIgURe 10: Continued. 


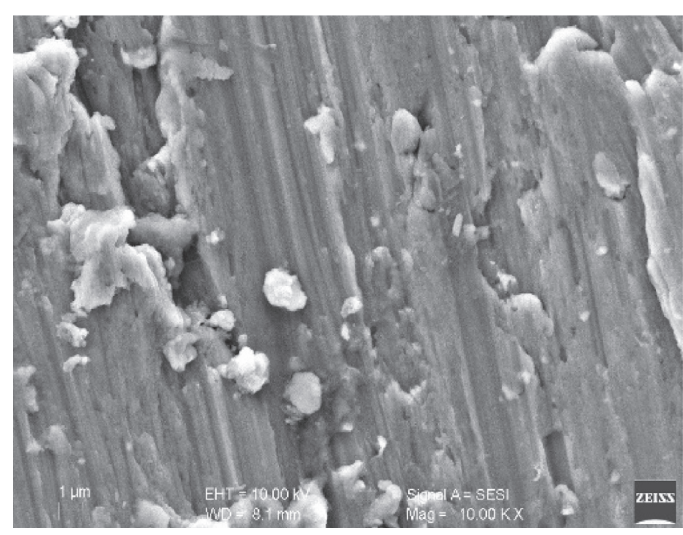

(c)

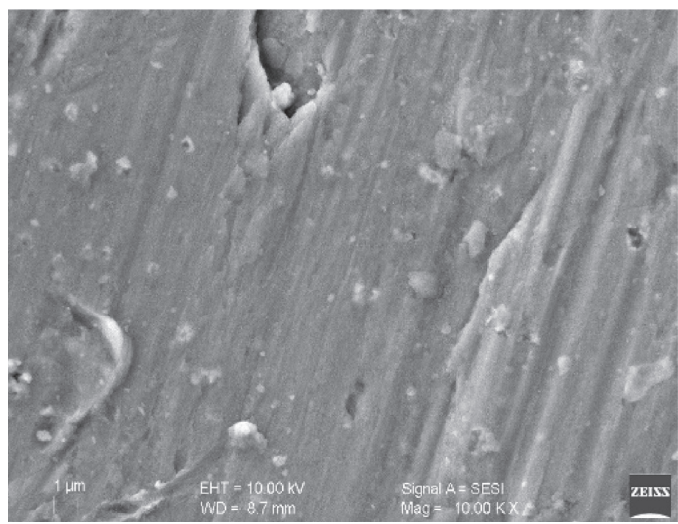

(e)

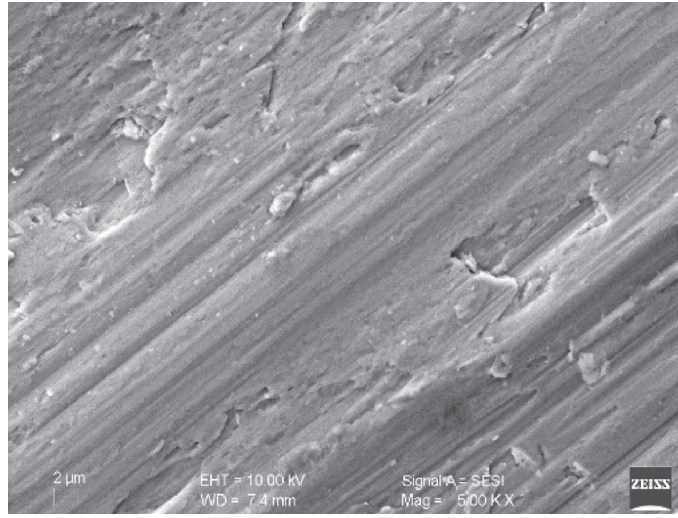

(g)

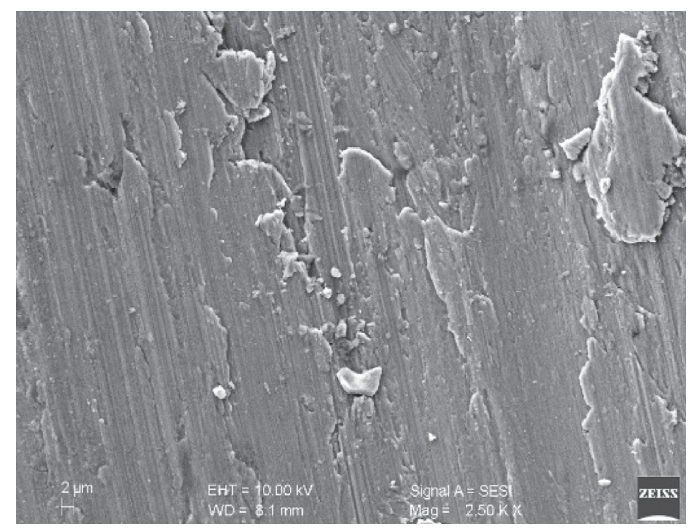

(d)

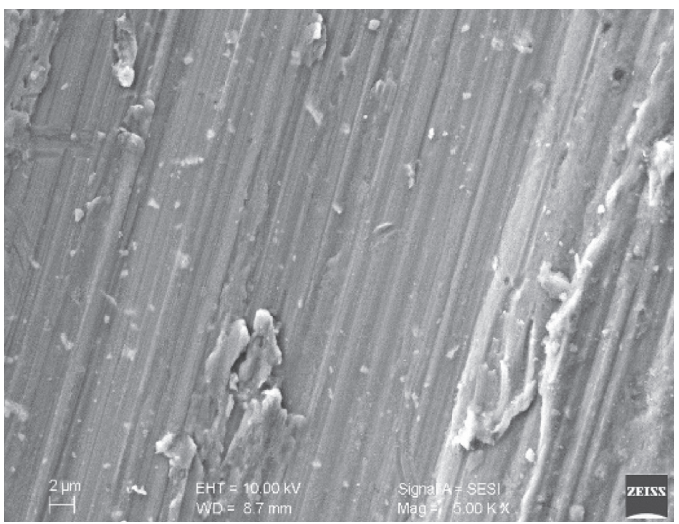

(f)

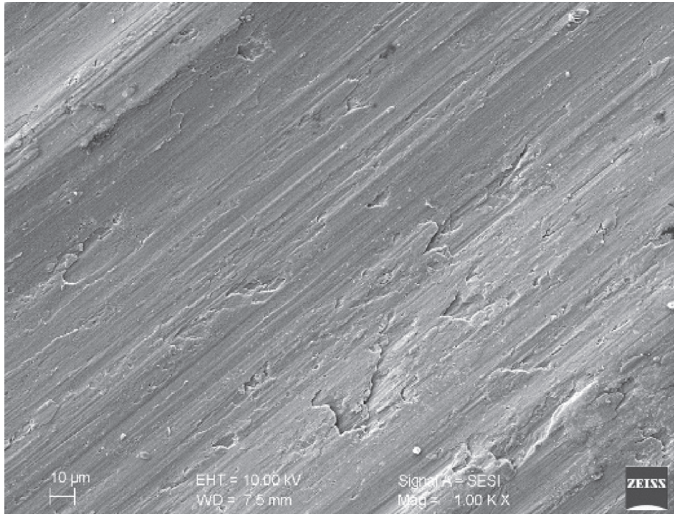

(h)

Figure 10: Micrographs of worn surfaces of as-cast and age-hardened specimens. (a) Al7075/B ${ }_{4} \mathrm{C}-6$ wt.\% as-cast. (b) Al7075/B ${ }_{4} \mathrm{C}-6$ wt.\% age-hardened. (c) Al7075/ $\mathrm{B}_{4} \mathrm{C}-8$ wt.\% as-cast. (d) Al7075/ $\mathrm{B}_{4} \mathrm{C}-8$ wt.\% age-hardened. (e) $\mathrm{Al} 7075 / \mathrm{B}_{4} \mathrm{C}-10$ wt.\% as-cast. (f) $\mathrm{Al} 7075 / \mathrm{B}_{4} \mathrm{C}-10$ wt. $\%$ age-hardened. (g) Al7075/ $\mathrm{B}_{4} \mathrm{C}-12$ wt. $\%$ as-cast. (h) Al7075/ $\mathrm{B}_{4} \mathrm{C}-12$ wt.\% age-hardened.

increasing with an increase in the volume fraction of the reinforcements. The wear resistance further increases due to age hardening. These results are in agreement with those investigated by Rajesh et al. [9]. The increase in wear resistance in age-hardened specimens is may be due to the elimination of voids or porosity.

From Figures 6-9, it can be observed that the wear rate is decreasing with an increase in hardness, and it is in agreement with findings from Rajesh et al. [9] in which they proposed that hard reinforcement particulate is restricting the composites from getting soft and resulting in reduced wear rate. The lower wear rate of the composites is also because of fine grains and almost uniform distribution of the reinforcement, as shown in Figure 4.

3.4. Worn Surface. The surface morphologies of the as-cast and age-hardened Al7075/B $\mathrm{B}_{4} \mathrm{C}$ AMMCs, taken with field emission scanning electron microscopy (FESEM), are shown in Figures 10(a)-10(h). From the FESEM 
micrographs, it is observed that as-cast AMMCs are having more craters as compared to age-hardened AMMCs. Larger grooves are seen in the as-cast AMMCs which indicate that there is more wear rate in as-cast AMMCs. From the FESEMs of as-cast wear surfaces, it is seen that the grooves are becoming smaller and smaller with the increase in the reinforcement. The surface morphologies of age-hardened samples show that there is no significant difference with an increase in reinforcement. Therefore, it can be concluded that the wear resistance can be improved by age hardening of the prepared composites.

\section{Conclusions}

The Al7075/B ${ }_{4} \mathrm{C}(50 \mu \mathrm{m})$ composites were fabricated by stir casting using a vacuum furnace. The characterization of composites with different weight fractions of reinforcement materials $(6,8,10$, and 12 wt. $\%$ of reinforcements) is carried out. The following findings are observed:

(i) The microstructural study shows the homogeneous distribution of the reinforcement particles in the $\mathrm{Al} 7075 / \mathrm{B}_{4} \mathrm{C}$ composites and reduction in the porosity in the age-hardened $\mathrm{Al} 7075 / \mathrm{B}_{4} \mathrm{C}$ composites as compared to as-cast $\mathrm{Al} 7075 / \mathrm{B}_{4} \mathrm{C}$ composites

(ii) The age-hardened $\mathrm{Al} 7075 / \mathrm{B}_{4} \mathrm{C}$ composites show higher hardness and wear resistance as compared to as-cast $\mathrm{Al} 7075 / \mathrm{B}_{4} \mathrm{C}$ composites

(iii) The wear resistance of the composite is dependent on the sliding speed, applied load, microstructure, weight percentage of the reinforcement, and age hardening

(iv) The surface morphologies of the wear surfaces indicate that the presence of larger grooves means lower wear resistance of the composites

Therefore, the age hardening of the composites is recommended to further enhance the wear resistance.

\section{Nomenclatures}

$\begin{array}{ll}\text { Al7075: } & \text { Aluminium alloy } 7000 \text { series } \\ \mathrm{B}_{4} \mathrm{C}: & \text { Boron carbide } \\ \text { M6: } & \text { Al7075 }+6 \text { wt. } \% \text { of } \mathrm{B}_{4} \mathrm{C} \\ \text { M8: } & \text { Al7075 }+8 \text { wt. } \% \text { of } \mathrm{B}_{4} \mathrm{C} \\ \text { M10: } & \text { Al7075 }+10 \text { wt. } \% \text { of } \mathrm{B}_{4} \mathrm{C} \\ \text { M12: } & \text { Al7075 }+12 \text { wt. } \% \text { of } \mathrm{B}_{4} \mathrm{C} .\end{array}$

\section{Data Availability}

The data used to support the findings of this study are available from the corresponding author upon request.

\section{Conflicts of Interest}

The authors declare that they have no known conflicts of interest or personal relationships that could have appeared to influence the work reported in this paper.

\section{Acknowledgments}

The authors wish to thank the Department of Mechanical Engineering, KNIT, Sultanpur, U. P., India, for providing facilities and necessary support in conducting experiments.

\section{References}

[1] D. M. Shinde, P. Sahoo, and J. P. Davim, "Tribological characterization of particulate-reinforced aluminum metal matrix nanocomposites: a review," Advanced Composite Materials, vol. 29, pp. 1-28, 2020.

[2] D.-V. Dragut, P. Moldovan, M. Butu, and E. Usurelu, "Characterization of in-situ AA $6060 / \mathrm{AlB}_{2}$ metal matrix composites," UPB Scientific Bulletin, Series A: Applied Mathematics and Physics, vol. 73, no. 4, pp. 1-10, 2011.

[3] N. S. Stoloff and D. E. Alman, "Innovative processing techniques for intermetallic matrix composites," Materials Research Society, vol. 194, pp. 31-43, 1990.

[4] J. Goni, I. Mitxelena, and J. Coleto, "Development of low cost metal matrix composites for commercial applications," Materials Science and Technology, vol. 16, no. 7-8, pp. 743-746, 2000.

[5] C. Fenghong, C. Chang, W. Zhenyu, T. Muthuramalingam, and C. Chang, Effects of Silicon Carbide and Tungsten Carbide in Aluminium Metal Matrix Composites, Springer Silicon, Berlin, Germany, vol. 11, 2019.

[6] I. Manivannan, S. Ranganathan, S. Gopalakannan, S. Suresh, K. Nagakarthigan, and R. Jubendradass, "Tribological and surface behavior of silicon carbide reinforced aluminum matrix nanocomposite," Surfaces and Interfaces, vol. 8, pp. 127-136, 2017.

[7] K. M. Shorowordi, A. S. M. A. Haseeb, and J. P. Celis, "Tribosurface characteristics of $\mathrm{Al}-\mathrm{B}_{4} \mathrm{C}$ and $\mathrm{Al}-\mathrm{SiC}$ composites worn under different contact pressures," Wear, vol. 261, no. 5-6, pp. 634-641, 2006.

[8] A. M. Rajesh, M. Kaleemulla, and S. Doddamani, "Effect of addition of $\mathrm{SiC}$ and $\mathrm{Al}_{2} \mathrm{O}_{3}$ on wear behavior of hybrid effect of addition of $\mathrm{SiC}$ and $\mathrm{Al}_{2} \mathrm{O}_{3}$ on wear behavior of hybrid aluminum metal matrix composites," Acta Technica CorviniensisBulletin of Engineering, vol. 12, pp. 42-52, 2019.

[9] A. M. Rajesh, M. K. Kaleemulla, and S. Doddamani, "Effect of heat treatment on wear behavior of hybrid aluminum metal matrix composites," Tribology in Industry, vol. 41, no. 3, pp. 344-354, 2019

[10] K. M. Shorowordi, T. Laoui, A. S. M. A. Haseeb, J. P. Celis, and L. Froyen, "Microstructure and interface characteristics of $\mathrm{B}_{4} \mathrm{C}, \mathrm{SiC}$ and $\mathrm{Al}_{2} \mathrm{O}_{3}$ reinforced $\mathrm{Al}$ matrix composites: a comparative study," Journal of Materials Processing Technology, vol. 142, no. 3, pp. 738-743, 2003.

[11] A. Leyland and A. Matthews, "On the significance of the H/E ratio in wear control: a nanocomposite coating approach to optimised tribological behaviour," Wear, vol. 246, no. 1-2, pp. 1-11, 2000.

[12] V. K. Sharma, V. Kumar, and R. S. Joshi, "Experimental investigation on effect of RE oxides addition on tribological and mechanical properties of Al-6063 based hybrid composites," Materials Research Express, vol. 6, no. 8, pp. 1-33, 2019.

[13] R. Hariharan and R. J. G. R. Nimal, "Experimental investigations on material characteristics of $\mathrm{Al}$ 6061- $\mathrm{TiB}_{2} \mathrm{MMC}$ processed by stir casting route," Middle-East Journal of Scientific Research, vol. 12, no. 12, pp. 1615-1619, 2012. 